\title{
AN INTEGRATED RANKING PROCEDURE FOR REPLACEMENT DECISIONS OF CRITICAL MEDICAL EQUIPMENTS
}

\author{
Tugba Efendigil \\ Department of Industrial Engineering \\ Yildiz Technical University \\ Istanbul, TURKEY \\ E-mail: tugbae@yildiz.edu.tr
}

\begin{abstract}
Hospitals and healthcare centers should take decisions on processes for acquisition, use, maintenance and replacement of medical equipments during their life cycle. Besides, managing large number of medical equipments is a complex and critic operational issue regarding an effective maintenance management which reduces operational costs at a significant ratio. The aim of this paper is to propose an integrated ranking procedure for replacement decisions in a health care setting including both quantitative and qualitative criteria. Both Analytical Hierarchy Process (AHP) and Grey Relational Analysis (GRA) techniques are integrated to make a prioritization of the criteria. A numerical illustration is applied to the proposed model.
\end{abstract}

Keywords: Analytic hierarchy process, Grey relational analysis, medical equipment, replacement

\section{Introduction}

Hospitals and healthcare centers utilize expensive and complex electro-mechanical equipments. During the life cycle of medical equipments, the decisions on maintenance and replacement are faced considering a multitude of factors with various uncertainties. The maintenance/replacement decisions are typically based on subjective reasons along with a scientific analysis.

A few studies have been proposed models to design the replacement/maintenance decision process. While, the most of these models only regard the quantitative information, qualitative factors such as technical obsolescence, safety and user friendliness are difficult to consider. In some sectors, notably health care, these qualitative factors are important as well as quantitative ones.

The aim of this paper is to develop a ranking procedure for prioritizing both quantitative and qualitative criteria that may influence the replacement decisions of critical medical 
IJAHP Article: Efendigil/An Integrated Ranking Procedure For Replacement Decisions of Critical Medical Equipments Submitted to the International Journal of the Analytic Hierarchy Process

equipment in a health care setting to help the hospital administrative level managers. To handle ambiguity in circumstances, an integrated model is proposed by utilizing decision making techniques. The model is applied to the University Hospital in Leuven (UZL) in cooperation with the hospital's technical division considering the insights of the implementation delivers.

\section{Literature review}

Replacement decisions generally are based on economics rather than on reaching the end of its physical service life. A piece of equipment may have many years of service life remaining beyond the point at which it has become uneconomical to operate it (Sepulveda et al., 1984). However Mummolo et al. (2007) claimed that the replacement analysis based on cost models could fail in the healthcare context since non-economical factors, such as technological obsolescence, medical staff satisfaction and patient safety, are all vitally important in the replacement decision.

In 1992, Fennigkoh developed a simple mathematical model to identify and prioritize medical equipment in need of replacement. The model contains a total of ten attributes addressing four primary replacement issues as follows; (1) equipment service and support (age, maintenance cost, downtime, end of manufacturer support), (2) equipment function (life support devices, therapeutic devices, diagnostic devices, analytical/support devices), (3) cost benefits, (4) clinical efficacy and preference. The output of the model is replacement priority value.

Christer and Scarf (1994) developed a mathematical replacement model in the context of medical equipment where factors such as service and risk play a role in replacement decision-making. Their model took into account subjective considerations which are difficult to quantify. The terms to be used: (1) equipment expected operating cost in its ith year of operation; (2) expected maintenance cost per year for equipment in its ith year, (3) total expected maintenance and operation cost per year for equipment in its ith year of operation, (4) usage of an equipment in year i relative to usage in year 1, (5) penalty measure for equipment in its ith year, (6) scrap value or resale valued of equipment $i$ years old, (7) purchase cost of equipment, (8) discount factor, (9) remaining life of existing equipment expressed in months or years, (10) economic life of new replacement equipment measured in years, (11) age of existing equipment in years

Rajasekaran (2005) developed an equipment replacement planning system (ERPS) to identify equipment most in need of replacement in order to optimize the utilization of capital budget resources, the attention to patient safety and efficiency for of the healthcare process. Rules have been developed to assist in determining which equipment should be prioritized for replacement. The rules are defined as follows; (1) technical (termination of product support, age of device compared to its estimated useful life, failure rate, clinical obsolescence, usability, physical condition); (2) safety (risk, technology related incidents, use-errors, recalls and alerts); (3) financial (cost of ownership compared to acquisition cost, financial impact of downtime, availability of backup, standardization).

Mummolo et al. (2007) proposed a fuzzy inference model to identify the equipment to replace in order to achieve the goals of reducing expenditure in a hospital structure and to increase patient and medical staff satisfaction. The model considers both linguistic and quantitative parameters in order to include many of the factors that actually influence International Journal of the Analytic Hierarchy Process

2

Vol. 3 Issue 12011

ISSN 1936-6744 
replacement decisions. The model structure includes seven different input parameters and one output as follows; (1) maintenance ratio, (2) mean downtime ratio, (3) age ratio, (4) usage ratio, (5) redundancy ratio, (6) life support, (7) technological obsolescence, whereas the output is priority replacement index.

Ouda et al. (2010) used Fault Tree Analysis to model the replacement process. Authors determined four major criteria for replacement decision as (1) hazards and alerts (2) useful life ratio, (3) cost, (4) vendor support. Those criteria are utilized to prepare a priority list of equipment that should be replaced.

We prepare a list of decision criteria to get ranked for an effective replacement analysis of critical medical equipments. After considering all the publications explained above, Table 1 shows the decision criteria and their definitions under main categories.

Table 1. Replacement decision criteria and their explanations for critical medical devices

$\begin{array}{ll}\text { Technical } & \text { Age of device: Length of time that equipment has been operating. } \\ \text { - } & \text { Failure rate: Number of repairs per year can be calculated ad total } \\ \text { number of repairs/age of device Failure rate: Recurrent failures of the } \\ \text { same component like electrical, mechanical, or other failures. } \\ \text { - Usage ratio: Scoring system such as; more than } 6 \text { hours per day=3; } \\ \text { between 0-6 hours per day=2; not daily use=1. } \\ \text { Usability: The number of occurrences for the usability of an equipment } \\ \text { which is sent to clinical engineering to be fixed and do not have any } \\ \text { problems. }\end{array}$

$\begin{array}{ll}\text { Economical } & \text { Total cost of ownership: Lifetime cost for maintenance and repairment } \\ \text { of a device added to acquisition cost. } \\ \text { - }\end{array}$

\section{The proposed procedure}

International Journal of the Analytic Hierarchy Process
Vol. 3 Issue 12011

ISSN 1936-6744 
IJAHP Article: Efendigil/An Integrated Ranking Procedure For Replacement Decisions of Critical Medical Equipments Submitted to the International Journal of the Analytic Hierarchy Process

An integrated ranking procedure is proposed to evaluate the decision criteria. Figure 1 depicts the proposed procedure to prioritize the criteria for replacement decision on critical medical devices.

Figure 1. The proposed methodology

The proposed procedure includes both Analytical Hierarchy Process (AHP) and Grey Relational Analysis (GRA) techniques as integrated. A numerical example was applied to show the details of this procedure.

\section{Conclusion}

International Journal of the Analytic Hierarchy Process 
IJAHP Article: Efendigil/An Integrated Ranking Procedure For Replacement Decisions of Critical Medical Equipments Submitted to the International Journal of the Analytic Hierarchy

Process

Replacement analysis is one of the significant issues in healthcare. Controlling and managing the large amount of medical equipments is a time and cost consuming process which sometimes may result with fatal consequences for patients. Traditionally, replacement analysis is based on cost models, however some non-economical factors should be considered in this decision process. Therefore, an integrated ranking procedure is proposed to help the decision makers to evaluate the replacement decisions. The literature has been investigated and three main criteria as technical, economical and noneconomical and their sub-criteria are defined. With the help of expert's opinion, in the first step AHP and in the following step GRA techniques will be applied. The results and the discussion will be presented as a conclusion of this study.

\section{REFERENCES}

Christer, A.H., \& Scarf, P.A. (1994). A Robust Replacement Model with Applications to Medical Equipment, Journal of Operational Research Society. 45(3), 261-275.

Fennigkoh, L. (1992). A Medical Equipment Replacement Model. Journal of Clinical Engineering, 7(1), 43-47

Mummulo, G., Japigia, V., \& Bevilacqua, V. (2007). A fuzzy approach for medical equipment replacement planning, Third International Conference on Maintenance and Facility Management.

Ouda, B.K., Mohamed, A.S.A., \& Saleh, N.S.K. (2010). A simple quantitative model for replacement of medical equipment proposed to developing countries.5th Cairo International Biomedical Engineering Conference, Cairo, Egypt, December 16-18.

Rajasekaran, D. (2005). Development of an automated medical equipment replacement planning system in hospitals. IEEE 31st Annual Northeast Bioengineering Conference. New Jersey, pg.52-53.

Sepulveda, J.A., Souder, W.E.,\& Gottfried, B.S. (1984). Schaum's outline of theory and problems of engineering economics, McGraw-Hill, Inc. 